\title{
THE LIFE TABLE OF Spodoptera pectinicornis Hampson AS BIOLOGICAL CONTROL AGENT OF WATER LETTUCE (Pistia stratiotes L.) WEED
}

\author{
${ }^{1}$ Lyswiana Aphrodyanti, ${ }^{2}$ Abdul Haris, ${ }^{3}$ Lidia Luisa Momongan \\ ${ }^{1}$ Department of Plant Protection plant, Faculty of Agriculture \\ ${ }^{2}$ Department of Soil, Faculty of Agriculture \\ ${ }^{3}$ Department of Plant Pests and Diseases, Faculty of Agriculture \\ University of Lambung Mangkurat, Banjarbaru, South Kalimantan, Indonesia
}

Email: aprhrodyanti13@yahoo.com

\begin{abstract}
The table of life can provide information on birth (natality), death (mortality) and the opportunity to breed, so it can be used as a parameter of the behavior of population development. The purpose of this study was to determine the calculation of life table of $S$. pectinicornis Hampson as biological control agent of water lettuce ( $P$. stratiotes) weed.The table of life is done by observing survival ability, mortality and fecundity of $S$. pectinicornis of a cohort of 300 eggs by looking at all the stages from egg, larva, pupa, and imago, and fecundity of female imago per day. The research was conducted in a condition of unlimited food resources and environment free of natural enemies. Parameters observed were gross reproductive rate (GRR), net reproductive rate (Ro), average of generation time (T), intrinsic rate of growth $(r)$, and limited rate of growth $(\lambda)$. The research result of the life table calculation showed that GRR value was 350.29 , the value of net reproductive rate (Ro) was 19.59 descendants, the average of generation time ( $T$ ) was 29.47 days, the value of intrinsic rate of accretion ( $r$ ) was 0.10 and the value of limited rate of accretion $(\lambda)$ was 1.11 .
\end{abstract}

Keywords: biological control, control agent, Spodoptera pectinicornis, water lettuce

\section{INTRODUCTION}

South Kalimantan is a region with vast water areas and widely used by the people as tourism areas, transportation infrastructure and reservoirs. But there are disturbing obstacles that is the water weed. Water lettuce (Pistiastratiotes L.) is one of aquatic weeds that can cause problems in our waters. Its ability to colonize the surface of the water is relatively brief because of its rapid growth. This weed has spread widely in tropical and subtropical regions. Problems posed by water lettuce among others are disturbing irrigation, hydroelectric power sources, and shipping. In addition, water lettuce can cause the loss of water through evapotranspiration resulting in shallowingand reduced oxygen in the water and water productivity. Various attempts have been made such as taking it away to the land, but quickly the water lettuce returnsto fill up the water surface and the effort requires a large workforce making it less effective and the cost is not cheap. Utilization of natural enemy of water lettuce is considered to be better than other ways of control (Aphrodyanti, 2007).

Spodoptera pectinicornis Hampson (Lepidoptera: Noctuidae) is one of herbivore insects that is used as biological control agent of water lettuce weed. According to Kasno (2003), the insect acting as natural enemy has considerable potential and has undergone study as biological control of weed. Moreover, the insects are generally able to multiply rapidly and also have a relatively narrow host range so they can be used as potential biological agents. S. pectinicornis is known to have a relatively short life cycle of around 35 days with larval development period of 17-20 days. In larval stage it is active as water lettuce eater and can cause very real damage (Texas A \& M University, 2003).

Basically most of the living beings population is not formed from the same individuals. There are a variety of ages and body sizes that vary according to age. Food and space needs of each individual in the population in general are different, corresponding to age and body size. Each egg produced by a female insect for some time (during the egg stage) does not have much effect on the population because the egg does not move, does not eat nor multiply. Individual population in the next stage of development is already busy looking for food and copulation so that the risk of death is greater (Tarumingkeng, 1992). 
One initial step in studying the development of an insect population is by knowing the demographic aspects. Demography is the quantitative analysis of the characteristics of a population, especially its relationship with the population growth patterns, resilience relationships, and population movement. Demographic aspects of a population can be found in the table of life (Carey, 1993). According to Price (1997), the table of life is a summary statement about the life of individuals in the population or groups. Tarumingkeng (1992) added that the table of life can be used to calculate various statistics of the population that can provide information about birth (natality), death (mortality), and a chance to breed, so it can be used as a parameter of the behavior of population development. Information that can be obtained from the table of life is a systematic description of the mortality and survival of a population. Such information is basic information necessary to examine changes in the density and rate of growth or decline of a population (Price 1997; Smith 1990). Table of life can also help us to decide the appropriate control techniques to determine the life strategies of the pests and can determine the rate of growth in the propagation of biological agents.

Pearl (1928) in Price (1975) introduced the life table in ecology in 1928, which was a summary of death of the population members. Horizontal life table (cohort) was a life table of static systems that could not be applied/apply to all organisms, particularly long-lived organisms.

In Indonesia, research of $S$. pectinicornisbiology was still very little, both on the development and the life cycle because of the difficulty of determining the number of instar larvae as there was no residual exuviaemaking it difficult to observe the change of skin as an indicator of larval development. In 2007 a research was conducted by Aphrodyanti on the table of life of $S$. pectinicornis biological agent in Bogor, West Java. The research result indicated that the extent of damage could be influenced by climatic conditions and altitude. During the rainy season the breakdown rate was low, while in the dry season the level of damage was high. The higher the altitude of a location the lower the level of damage would become. This was what underlied the researchers to understand the population growth with climatic conditions and altitude of a location so that when the insects released in the field it could meet the target to control water lettuce ( $P$. stratiotes) weed. The purpose of this study was to determine the calculation of the table of life of S. pectinicornis as biological control agent of water lettuce ( $P$. stratiotes L.) weed.

\section{MATERIALS AND METHODS}

\section{Insects Test Preparation}

Propagation of test insects was done by finding water lettuce that looked damaged due to the feeding activity of $S$. pectinicornis from the field. The water lettuce was taken and collected and observed carefully and thoroughly to determine whether the damage was caused by the larvae of $S$. pectinicornis. The symptomatic water lettuce was then put into containers such as big plastic bags and arranged well, the water lettucewas then placed intoa bowl with water in it and put in a netted cage measuring $75 \mathrm{~cm} \times 75 \mathrm{~cm} \times 75 \mathrm{~cm}$ in order to keep good air circulation.

\section{Maintenance S. pectinicornis in Laboratory}

The water lettuce taken from the field and placed in the container of water basin and suffered damage by larvae feeding activity would be placed on top of the fresh water lettuce so that the larvae could move and gotnew food so that it could reach the pupa phase. Pupae were collected and placed in a plastic jar with a diameter of $14 \mathrm{~cm}$ that at its base absorbent paper waslaid and wet cotton was given to keep it moist. Observation of male and female imagoes was conducted. Male and female imagoes were moved into an enclosure containing fresh water lettuce and given $10 \%$ honey in hung cotton. Imagoes were let to mate (copulate) and laid eggs on the water lettuce. So it went on so new imagoeswere found and ready for use in this study.

\section{Life Table Testing}

Testing of the table of life on the plant begun by inserting 10 individual $S$. pectinicornis imagoes $(5$ males and 5 females) into a cylindrical mica plastic tube that the top part of it coated withgauze and in the mid there was a hole that serves to insert the imagoes and after 24 hours the imagoes were taken out and the search of egg groups on water lettuce leaves was carried out. Next, observation was made on a total of 300 eggs found on the water lettuce to hatch into larvae and transferred to a new container containing water lettuce. Calculations were carried out 
every day to determine the number of individuals that were still alive and dead. Larvae reared to become pupae and imagoes. Female and male imagoes that managed to emerge were also calculated to determine the sex ratio. Furthermore female imagoes mated with male imagoes and allowed to lay eggs on the water lettuce until all imagoes died.

\section{Data analysis}

Data analysis was performed after reconstruction of the life table. The parameters observed in this study included the duration of development time required for eggs to become imagoes, duration of life of imagoes, the number of eggs laid and development needed since the eggs were laid by imagoes to hatch into first instar larvae.

Demographic parameters according to Birch (1948) that were calculated include:

1. Gross reproductive rate (GRR), calculated by the equation:

$$
\mathrm{GRR}=\Sigma \mathrm{mx}
$$

2. Net reproductive rate (Ro), calculated by the equation:

Ro $=\Sigma \mid x m x$

3. Average of generation time (T), calculated by the equation:

$$
\mathrm{T}=\Sigma \mathrm{x}|\mathrm{xmx} / \Sigma| \mathrm{xmx}
$$

4. Intrinsic accretion rate ( $r$ ), computed by the equation:

$$
r=\ln R o / T
$$

5. Limited accretion rate $(\lambda)$, calculated by the equation:

\section{Explanation:}

$$
\lambda=e^{r}
$$

$x \quad$ : cohort age class (day);

Ix : proportion of individuals living at the age of day- $x$

$\mathrm{mx} \quad$ : specific fecundity of individuals in age class of day-x.

\section{RESULTS AND DISCUSSION}

From the calculation of the table of life many things could be discovered about the livelihood of $S$. pectinicornis. One of them would be the chance of survival curve of individuals living at all stages from egg, larva, pupa, and imago (Ix) and fecundity of female imago per day (mx) (Figure 1). Observations and calculations were carried out every day against $S$. pectinicornis population ranging from egg stageto female imago started to reproduce eggs. The data obtained were arranged in the form of parameters of life table (Appendix 1).

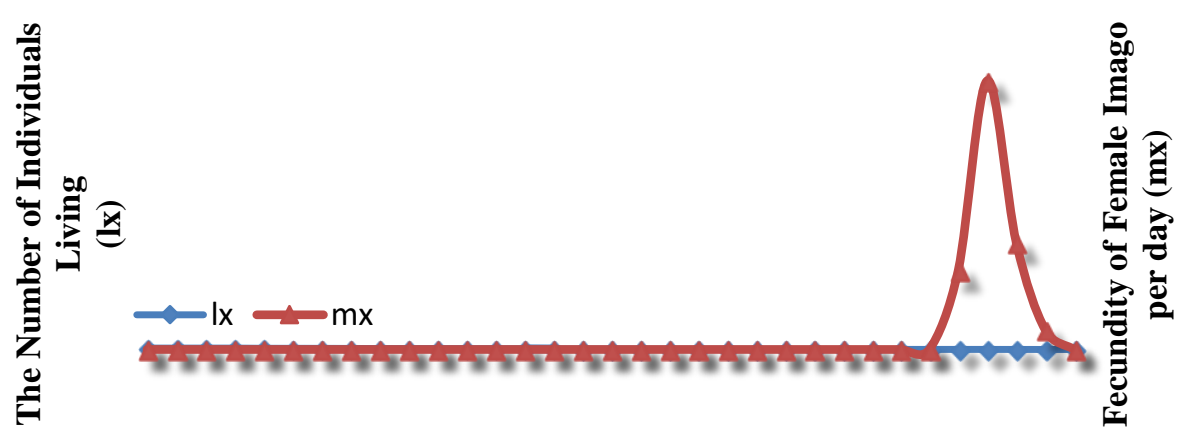

Individual Ages (day)

Figure 1. Survival curve and fecundity of $S$. pectinicornis

Based on the graph it could be seen that the chances of survival (Ix) of $S$. pectinicornis started to decline on day $4(\mathrm{x}=$ 3.5) where the eggs hatched into first instar larvae and many suffered death and continued to decline. The chance of survival curve showed many deaths occurred in aging adult individuals or in the late stage of development.
Mx value indicates the number of female eggs produced by female parent of day- $x$ old, and was calculated after considering the sex ratio of 1: 1 . Figure 1 presents the length of life curve (Ix) and the average fecundity per day $(\mathrm{mx})$. From the curves, it was known that the laying of eggs began on day $29(x=28.5)$, which mean tone day after the first female imago appeared and 
after copulating it could directly lay eggs on the leaves of water lettuce. It was considered good considering the age of female imago and short period of oviposition time, thus the time efficiency of egg-laying and the eggs laid in large quantities could sustain the populations of $S$. pectinicornis. Peak of egg-laying occurred on day $30(x=29.5)$ and after day 31 it decreased as a result of increasing age of female imago and began to experience death.
The older the age ofimago the lower its fecundity would be.

Calculation results of the table of life of $S$. pectinicornis included gross reproductive rate (GRR), net reproductive rate (Ro), length of generation time $(T)$, intrinsic rate of accretion $(r)$, and limited rate of accretion $(\lambda)$, shown in Table 1 and calculation of demographic parameters in Appendix 2.

Table 1. Demographic parameters of $S$. pectinicornis

\begin{tabular}{cc}
\hline Parameter & Value \\
\hline Gross reproductive rate (GRR) & 350.29 \\
Net reproductive rate (Ro) & 19.59 \\
Average of generation time $(\mathrm{T})$ & 29.47 \\
Intrinsic rate of accretion $(r)$ & 0.10 \\
Limited rate of accretion $(\lambda)$ & 1.11 \\
\hline
\end{tabular}

The research result showed that GRR value of $S$. pectinicornis was 350.29 individuals per parent per generation. GRR value is the average number of female offsprings per parent produced by $S$. pectinicornis individual whose life has reached the maximum age. Net reproductive value (Ro) was 19.59 individuals per parent per generation. The value showed the average number of offsprings produced by a female parent of each generation after accounting for death or life chances (Ix). The average value of generation time $(T)$ describes the time it takes from the moment the egg is laid until the female imago derived from the egg produces offsprings. S. pectinicornis showed generation timeof 29.47 days so within the 29 days the newly emerging female individuals were able to reproduce offsprings. The intrinsic rate of accretion $(r)$ was 0.10 individual per individual per day. Based on the value of $r$ that was obtained, the calculation result of limited rate of accretion $(\lambda)$ was 1.11 , which meant the population of $S$. pectinicornis would experience population multiplication of 1.11 individual per individual per day.

$S$. pectinicornis insect is herbivorous insect that undergo complete metamorphosis that develops from egg to larva, then pupa, and finally into imago. The survival of an individual could be seen from the imago coming out in the life cycle from egg to pupa and then became imago. S. pectinicornis has a relatively short life cycle and has quite high power to survive, the larvae have the longest lifespan and have the ability to control the water lettuce with high level of food consumption, so they have potential as biological control agents against the water lettuce $(P$. stratiotes) weed.

Chance of survival curve of $S$. pectinicornis generally showed the highest mortality rates occurred during early development followed by a slow decline throughout its life (Figure 1). The research result showed that $S$. pectinicornis including type III showed greater mortality in a population of young age or early stage. The pattern of success like this was very commonly found in insect species. This was in line with what was stated by Price (1997) that there were three types of survival curves, namely type I, type II and type III. The type I curve described the death of organism in small amount when the populationwas of young age and the death in large number when the population wasof older age, type II showed the mortality rate was constant, while type III showed greater mortality occurred at young age population.

Life expectancy of eggs was greater than the larvae and pupae. This was due to the egg had not been contaminated by outside factors because it was still wrapped with egg shells and fibers released by female imago so it was protected form dryness and predators. During observation of the eggs in the laboratory there were no significant obstacles or only a few eggs that did not hatch but the cause were not known with certainty. According to Elseth and Baumgardner (1981) the need for food and space of each individual in the population in general differed according to age and body size. The eggs produced by female insect for some time (during the egg stage) did not have much effect on the 
population because the egg did not move, did not eat nor multiply. Population individuals in the next stage of development would be busy looking for food and copulation so that the risk of death was greater.

The larvae were very susceptible to outside environmental factors because they were no longer wrapped with egg shells and fibers released by female imago as in eggs and were already busy looking for food. The research result showed greater mortality occurred when the population was of young age and fewer when the population was of older age. During the process of development the larvae did not change morphologically, only the body size of larvae got bigger the older they were. This was in line with the increasing number of food consumption that the larvae required for its development. In the late-instar larvae became shortened and somewhat wrinkled (Aphrodyanti, 2007).

In the late-instar larval stage, the larva began to gnaw water lettuce leaf base that is rather thick and entered the prepupa stage, at this stage the larva could undergo decomposition because of immersion in water so that it failed to become a pupa. In the pupal stage there were some pupae that failed to become imago, the pupae rotted and dried. Especially for pupa, because it was no longer active/silent and undergo a physiological process so that at the development stage there wasa total overhaul of the body, namely the formation of complete organs as an adult insect that required enormous energy (Aphrodyanti, 2007).

The length of $S$. pectinicornis imago life was also relatively short i.e. approximately one week. The number of female individuals in a population might affect the value of fecundity, whereas the number of eggs produced by female imago could show the level of suitability of individuals with its host plant (Aphrodyanti, 2007).

Balance of life or life table is an approach in studying the population dynamics. According to Tarumingkeng (1992) the life table was a reference in the weed control strategy corresponding to the death condition of the organism in question. Table of life is the basic data that provide biological information in the field of insect population dynamics and can be used to determine the reproductive potential of insects or pests in a given physical environment. Metcalf and Luckman (1982) stated that the information of life table was a useful tool for determining the weakest time of the life cycle of a type of pest. In addition, key factors in controlling insect populations could be determined, i.e. environmental obstacle factors among others physical environmental factors, food and natural enemies.

According to Price (1997) the value of reproduction provided an overview of the relative contribution of an individual at a certain age toward the population. The reproduction value usually increased at the start of reproduction, then decreased as the insects became older. The value of reproduction was also used as a reference in releasing imago to the field. The gross reproductive rate (GRR) was the average number of female offsprings per parent produced by $S$. pectinicornis individual whose life reached a maximum.

Based on the research that has been done it can be seen that the GRR value is 350.29 individuals per parent per generation, where the GRR value is slightly bigger than that of the research done by Aphrodyanti (2007) i.e. 326.885. The value of net reproductive rate is 19.59 individuals per parent per generation. The value of net reproductive rate (Ro) is the average number of offsprings produced by a female parent of each generation after accounting for death or life chances (Ix) of $S$. pectinicornis. The result of this calculation also showed that the population of S. pectinicornis would increase 19 folds each generation within unlimited environmental conditions. This Ro value was smaller than that of the research conducted by Aphrodyanti (2007) i.e. 49.915. The high GRR and Ro values showed levels of life conformity of insects to the host plant. A population would increase if it has Ro $>1$, decrease if Ro $<1$ and stable when Ro $=1$ (Price, 1997). The research result showed Ro value was 19.589 Ro $>1$ indicated an increase in population of $S$. pectinicornis meaning population of the biological agency increased and would not become extinct.

The average of generation time $(T)$ is the time required since the egg is laid until the female imago that comes from the egg produces half of its offsprings. S. pectinicornis showed generation time of 29.47 days so within the 29 days the female individual that emerged would be able to reproduce offsprings. The condition of low temperature area could slow down reproduction of insects, so the life length of insects was shorter so that the number of generations and the number of insect populations tended to be less (Duyck et al, 2010). Lowland area has high temperature and high climatic conditions so that the length 
of life of $S$. pectinicornisis slightly longer than that in the research conducted by Aphrodyanti (2007) i.e. 25.599 days. The smaller the value of $\mathrm{T}$, the faster an organism multiplies. The length of life was also influenced by the availability of feed such as nutrients contained in water lettuce ( $P$. stratiotes) plant as feed for $S$. pectinicornis namely nitrogen as basic element needed for the metabolism of living beings (Bansode\&Purohit, 2013). This was in line with the research conducted by Ningrum (2015) that the imago fed with the treatment of low concentration NPK fertilizing would last longer than the imago with high concentration.

By knowing the value of Ro and $T$, the intrinsic rate of accretion ( $r$ ) of the generation could be determined. The intrinsic rate of accretion $(r)$ is the population growth in constant environment and unlimited resources. The value obtained was determined by various aspects related to the life cycle of the organism, namely death, birth, and time of development (Price, 1997). The value of research result of intrinsic rate of accretion $(r)$ of 0.10 individuals per individual per day, was calculated on the assumption that the population had a fixed schedule of $\mathrm{Ix}$ and $\mathrm{mx}$ and death occurred only by physiological factors (Price, 1975). The value of intrinsic rate of accretion is a constant for a constant condition. If the environmental conditions changed, then the $r$ value would also change. If the value of $r$ is less than zero, the species will fail to sustain life, but it did not mean that the higher the $r$ value of a species, the species would be more successful. The process of evolution would select a species so that $r$ value was high enough to be able to compete with other species, but low enough so that the rate of population multiplicationdid not result in resource exhaustion in the environment (Birch, 1948).

The value of research result of limited rate of accretion $(\lambda)$ of 1.11 meant the $S$. pectinicornis population would experience population multiplication of 1.11 individuals per individual per day. Limited rate of accretion is the population ratio between the existing population andfuture population based on a time unit i.e. day. In field conditions there might be differences, because of the environmental factors that affect the population, such as weather, predators and survival factors of the insect.

Demographic processes such as births, deaths, immigration and emigration, are all factors that affect the size and composition of a population. The timing of this process played an important role in the development of a population, for example, a population with a high pre-adult mortality would have a different structure from a population with high mortality rate at the time after the age of reproduction. The table of life is a table of survival and fecundity data of each individual in a population (Rockwood, 2006).

The research was conducted on a condition of unlimited food resources and an environment free of natural enemies, so the deaths that occurred could be caused by genetic conditions and environmental conditions at the time of testing. Based on the pattern of survival curve, it indicated that preadult early stage was susceptible to physical interference at the time of maintenance and quality of the food.

The study of life table of $S$. pectinicornis was conducted in a laboratory conditions at average daily temperature of $27.01^{\circ} \mathrm{C}$ with moisture of $74.75 \%$. Under such conditions, what needs to be done so that the $S$. pectinicornis biological agent is capable of controlling water lettuce (P. stratiotes) weed is establishingthe $S$. pectinicornis biological agent population in advance in nature. It is expected that by building their own population, $S$. pectinicornisb iological agent would be able to survive and control water lettuce $(P$. stratiotes) weed effectively, although in a relatively long period of time.

\section{CONCLUSIONS}

The result of the calculation through the table of life of $S$. pectinicornis namely the value of gross reproductive rate (GRR) was 350.29 , the value of net reproductive rate (Ro) was 19.59 descendants, the average of generation time (T) was 29.47 days, the value of intrinsic rate of accretion $(r)$ was 0.10 and the value of limited rate of accretion $(\lambda)$ was 1.11 .

\section{REFERENCES}

Aphrodyanti, L. (2007). Spodoptera pectinicornis (Hampson) (Lepidoptera: Noctuidae) as Biological Control of Water Letucce (Pistia stratiotes) Life Studies, Destructive Capabilities and Host Range. Thesis. Institut Pertanian Bogor. Bogor.

Bansode, G.M. \& Purohit, M.S. (2013). Effect of Different Level of Nitrogenous Fertilizer on Larval and Post Larval 
Development of Plutella xylostella (Linn.) Infesting Cauliflower. Journal The Bioscan (2): 545-548.

Birch, L.C. (1948). The Intrinsic Rate of Natural Increase of An Insect Population. Journal of Animal Ecology 17 (1): 15-12.

Carey, J.R. (1993). Applied Demography for Biologist With Special Emphasis On Insect. p 11-41. Oxford University Press. New York. USA.

Duyck, P.F., Kouloussis, N.A., Papadopoulos, N.T., Quilici, S., Wang, J.L., Jiang, C.R., Muller, H.G., \& Carey, J.R. (2010). Lifespan of a Ceratitis fruit fly increases with higher altitude. Biological Journal of the Linnean Society 101: 345-350.

Elseht, G.D. \& Baumgardner, K.D. (1981). Population Biology. 623 p. Van Nostrand Co. New York etc.

Kasno, Aziz KA, Soerjani M. (1979). Prospects for Biological control Of Weed in Indonesia. In: Proccedings $7^{\text {th }}$ Asian Pacific Science Society Conference: Bogor, 26-30 Nopember 1979. p 35-38. Biotrop. Bogor.

Ningrum, W. (2015). The Influence of Potassium Phosphorus Nitrogen Fertilizer on water lettuce (Pistia stratiotes L.) on the health of biological control Spodoptera pectinicornis (Hampson). Faculty of Agriculture. University of Lambung Mangkurat. Banjarbaru.

Price P.W. (1997). Insect Ecology. $3^{\text {th }}$ ed. John Wiley \& Sons, Inc. New York.

Rockwood, L.L. (2006). Introduction to Popuation Ecology. Blackwell Publishing. Oxford. Uited Kingdom.

Tarumingkeng, R.C. (1992). Dynamics of Insect Population Growth. Pusat Antar Universitas-IImu Hayat IPB. Bogor.

Texas, A. \& M. University (2003). Water lettuce leaf moth. Retrieved 15 April 2014 from http://bc4weed.tamu.edu/agents/wa terlettuceleafmoth.html 